\title{
DIFFERENTIATION OF RABBIT SPERM ANTIGENS FROM THOSE OF SEMINAL PLASMA
}

\author{
ALAN G. HUNTER \\ Department of Animal Science, University of Minnesota, \\ (Received 18th October 1968, revised 4th April 1969)
}

\begin{abstract}
Summary. Sperm-specific and sperm-coating antigens in rabbit seminal constituents were studied using agar-gel diffusion and immuno-electrophoresis. The antigenicity of ejaculated rabbit spermatozoa was due to two glycoprotein sperm-specific antigens of testicular origin and twelve seminal plasma antigens which coated the spermatozoa during passage through the reproductive tract. Two of the sperm-coating antigens originated in the testis, two in the epididymis and eight above the level of the vas deferens. Relationships between sperm-coating antigens and capacitation, and sperm-coating antigens and prevention of immunologically induced aspermatogenesis or immunologically induced infertility in the female were proposed.
\end{abstract}

\section{INTRODUCTION}

The antigenicity of mammalian spermatozoa has been accepted for 70 years (Landsteiner, 1899). But in 1960, Weil reported that rabbit epididymal spermatozoa lacked the antigenic material found on ejaculated spermatozoa and thus cast doubt on the inherent antigenicity of rabbit spermatozoa. Weil \& Rodenburg (1962) later demonstrated that the sperm cell was coated with antigenic materials, probably of seminal vesicle origin, during the process of ejaculation. Spermatozoa and seminal plasma have powerful and seemingly preponderant antigens in common. This has been established for man (Weil, Kotsevalov \& Wilson, 1956), guinea-pigs (Pernot, 1956), sheep (Hathaway \& Hartree, 1963), buffalo (Rao \& Sadri, 1960), cattle (Hunter \& Hafs, 1964) and rabbits (Weil \& Finkler, 1958).

The objectives of this study were to determine the origin of sperm-coating and sperm-specific antigens in the male rabbit's reproductive tract and to quantitate the number of sperm-coating antigens found in various segments of the male rabbit's reproductive tract.

\section{MATERIALS AND METHODS}

Semen was collected with an artificial vagina from Dutch-belted and New Zealand white rabbits and separated into cells and plasma within $10 \mathrm{~min}$ of collection by centrifuging at $12,000 \mathrm{~g}$ for $5 \mathrm{~min}$. The seminal plasma was removed and re-centrifuged while the spermatozoa were washed once or five 
times with $0.005 \mathrm{M}$-phosphate-buffered saline $(\mathrm{pH} \mathrm{7.4)}$. The washed spermatozoa were adjusted to a concentration of $80 \times 10^{6} / \mathrm{ml}$ with buffered saline and frozen until used.

Seminal plasma was collected from males which had been vasectomized 3 months before the collection of materials for this study and were free of any residual spermatozoa.

Suspensions of spermatozoa from the caput epididymidis, cauda epididymidis, vas deferens and testis were prepared by dissecting these organs from the reproductive tract and macerating each in phosphate-buffered saline $(\mathrm{pH} \mathrm{7.4)}$.

Normal sera were obtained from cows and goats before immunization. Fivetimes-washed, ejaculated, rabbit spermatozoa $\left(80 \times 10^{6} / \mathrm{ml}\right)$ were prepared as antigen. The immunization scheme consisted of intradermal injections of $2.5 \mathrm{ml}$ of washed rabbit spermatozoa mixed with $2.5 \mathrm{ml}$ of Freund's complete adjuvant into five sites in the scapular region. This was followed by 4-weekly injections of $2.5 \mathrm{ml}$ of the same antigen mixed with $2.5 \mathrm{ml}$ of Freund's incomplete adjuvant. In this manner, one cow and two goats were immunized with antigen. Two weeks after the fifth injection, each animal was bled by venipuncture, serum was recovered and then frozen until used.

Procedures for the Ouchterlony technique, the immuno-electrophoresis technique and the absorption technique were identical to those which have already been described (Hunter \& Hafs, 1964).

\section{RESULTS}

Interpretation of the diagrams in Text-fig. $1(\mathrm{c}, \mathrm{d})$ led to the conclusion that rabbit testis had five antigens capable of reacting with antibody to ejaculated spermatozoa. Of these, four were of testis origin and one of blood serum origin, probably due to the method of preparing the testicular suspension. The four testicular antigens represented two sperm-specific antigens and two seminal fluid antigens probably originating from cells lining the seminiferous tubules. Cross-reactions between testis and seminal plasma may have been due to leakage of sperm proteins and/or to secretions from the seminiferous tubules or rete testis which eventually were voided in seminal plasma. The two antigens present in spermatozoa and absent from seminal plasma were located by their inability to form chevrons with seminal plasma lines (Text-fig. 1d). Hunter \& Hafs (1965) also reported two sperm-specific antigens which originated in rabbit testis. Menge \& Protzman (1967) suggested that one or both of the sperm-specific antigens were involved in the antifertility reactions.

Absorption of antisera to spermatozoa with seminal fluid from a vasectomized male (Text-fig. 1d) revealed the spectrum of antigens originating before the vas deferens. Five testicular antigens and five or six epididymal antigens were still present. Epididymal sperm suspensions possessed the previous four testicular antigens not of blood serum origin and two additional antigens (Text-fig. 1c). One of the new epididymal antigens was identical to an antigen present beyond the tail of the epididymis since absorption with vasectomized seminal fluid removed it (Text-fig. 1d). Many of the testicular or epididymal antigens formed identities with seminal plasma antigens and ejaculated sperm antigens. The 

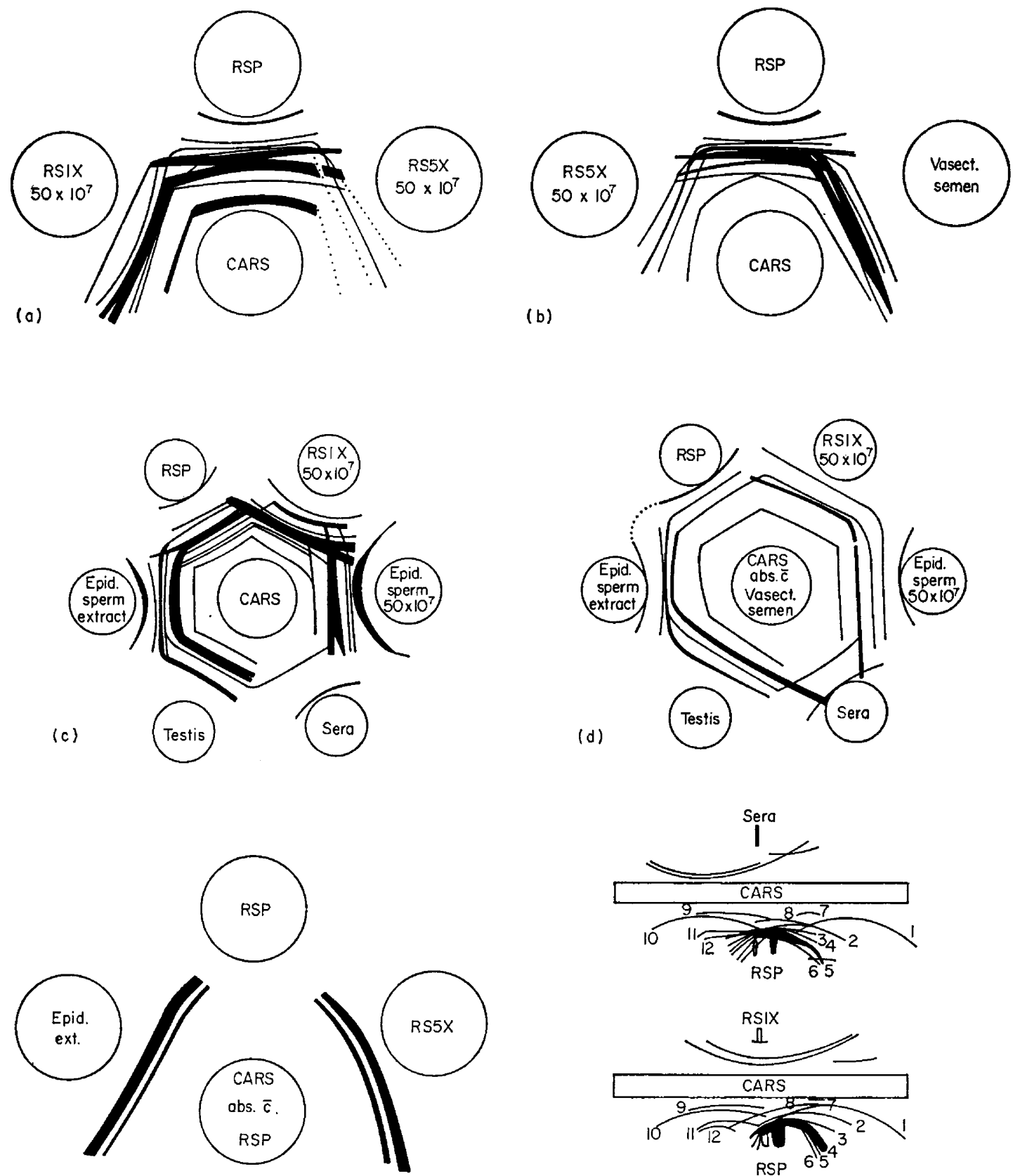

(e)

(f)

TeXr-FIg. 1. Precipitins in bovine serum against rabbit seminal products and blood serum. (a), (b), (c), (d) and (e) are diagrams of agar-gel diffusion plates and (f) is an immunoelectrophoresis plate. CARS $=$ Cow anti-rabbit ejaculated spermatozoa; abs. $\overline{\mathbf{c}}=$ absorbed with; RSP = rabbit seminal plasma; Sera = rabbit blood serum; RS1 $\times=$ rabbit spermatozoa washed once; $\mathrm{RS} 5 \times=$ rabbit spermatozoa washed five times; Epid. = rabbit epididymal spermatozoa; Testis = rabbit testis $(5 \% \mathrm{w} / \mathrm{v})$; Vasect. = seminal fluids from vasectomized rabbits. 
demonstration of antigenic materials in or on rabbit epididymal spermatozoa which reacted immunologically with antisera against ejaculated spermatozoa was contrary to the report of Weil (1960) but agreed with the findings of Hunter \& Hafs (1965) and Menge \& Protzman (1967).

Ejaculated spermatozoa possessed two sperm-specific antigens and twelve sperm-coating antigens. Absorption of antisera to spermatozoa with seminal plasma (Text-fig. le) revealed two lines opposite epididymal and ejaculated spermatozoa. These were the sperm-specific antigens. These two antigens stained as glycoproteins with $\alpha$-naphthol-paraphenylene-diamine after periodate oxidation (Crowle, 1961) and were of testicular origin.

Washing removed sperm-coating antigens, as only five to seven antigens were detected on once-washed ejaculated spermatozoa and only two antigens on fivetimes-washed ejaculated spermatozoa (Text-fig. la, b). Since the antisera were induced against five-times-washed ejaculated spermatozoa, twelve spermcoating antigens had to be present on the spermatozoa to explain the twelve lines produced with seminal plasma (Text-fig. la, b, f). Thus, sufficient spermcoating antigens were bound to the spermatozoa to induce antibody formation, but after washing, insufficient antigen remained to diffuse and produce detectable lines.

Seminal plasma removed from ejaculated spermatozoa usually formed nine, but sometimes twelve, precipitin bands when allowed to react with antibody to ejaculated spermatozoa (Text-fig. 1a, b, f). The sperm-coating antigens in seminal plasma originated as follows: testicular fluids contributed two; epididymal fluids contributed two; and organs beyond the vas deferens contributed five to eight antigens. At least six sperm-coating antigens were detected in the seminal fluid from a vasectomized male (Text-fig. 1b) and represent secretions beyond the vas deferens.

Each diagram in Text-fig. 1 may not show the maximum number of possible lines quoted in the text, due to certain lines fusing together and thus appearing as one broad line.

\section{DISCUSSION}

The physiological significance of sperm-coating antigens is just becoming evident. Hunter \& Nornes (1966) reported that a glycoprotein sperm-coating antigen of seminal plasma origin had the ability to reverse the capacitation process in rabbits. Sperm-coating antigens were part of the 'decapacitation factor' reported in rabbit seminal plasma by Bedford \& Chang (1962). Capacitation probably involves the removal or alteration of one or more of these sperm-coating antigens. Williams, Weinman \& Hamner (1964) reported that rabbit epididymal fluid also contained a 'decapacitation factor'. The present work has demonstrated the existence of sperm-coating antigens in the epididymis and it seems possible that these may also be involved in the capacitation phenomena.

Numerous reports summarized by Katsh (1959) and Tyler (1961) documented the fact that sterility in certain species can be induced by injecting semen into the body. This sterility was produced by antibodies against sperm- 
specific antigens rather than the sperm-coating antigens (Menge \& Protzman, 1967). In the female rabbit, Weil \& Roberts (1965) demonstrated that the formation of antibodies against rabbit seminal plasma had no effect on fertility. Edwards (1960), Weil (1960), Stevens \& Fost (1964) and Behrman \& Nakayama (1965) demonstrated that the sperm-specific antigens were less potent antigenically than those of seminal plasma. It is possible that antigens of seminal plasma origin block or coat the antigenic reactive sites on the surface of the spermatozoa and normally prevent immunologically-induced aspermatogenesis in the male or immunologically-induced infertility in the female.

\section{ACKNOWLEDGMENTS}

This paper is Journal Article No. 6704 from the Minnesota Agricultural Experiment Station. This investigation was supported in part by USPHS Grant HD 00816 and carried out in part under an NSF grant for Research Participation for High School Teachers. I wish to thank Dr Harold D. Hafs for his aid in formulating the early stages of this study and for supplying rabbit semen and seminal products.

\section{REFERENCES}

Bedford, J. M. \& Chang, M. C. (1962) Removal of decapacitation factor from seminal plasma by high-speed centrifugation. Am. 7. Physiol. 202, 179.

Benrman, S. J. \& Nakayama, M. (1965) Antitestis antibody: Its inhibition of pregnancy. Fert. Steril. $16,37$.

Crowle, A. J. (1961) Immunodiffusion. Academic Press, New York.

EDwards, R. G. (1960) Antigenicity of rabbit semen, bull semen and egg yolk after intravaginal or intramuscular injections into female rabbits. J. Reprod. Fert. 1, 385.

Hatiaway, R. R. \& HARTREe, E. F. (1963) Observations on the mammalian acrosomes: experimental removal of the acrosomes from ram and bull spermatozoa. 7. Reprod. Fert. 5, 225.

Hunter, A. G. \& HaFs, H. D. (1964) Antigenicity and cross-reactions of bovine spermatozoa. F. Reprod. Fert. 7, 357.

Hunter, A. G. \& Hafs, H. D. (1965) Differentiation of sperm protein from that of seminal plasma in rabbits. (Abstract). Fedn Proc. Fedn Am. Socs exp. Biol. 24, 700.

Hunter, A. G. \& Nornes, H. O. (1966) Sperm coating antigens and capacitation of rabbit sperm. 7. Anim. Sci. 25, 925.

Katsh, S. (1959) Immunology, fertility and infertility: a historical survey. Am. F. Obstet. Gynec. 77, 946.

LANDSTEINER, K. (1899) Zur Kenntnis der spezifisch und blutkorperchen wirkenden Sera. Zentbl. Bakt. Parasitkde, 25, 546.

Menge, A. C. \& Protzman, W. P. (1967) Origin of the antigens in rabbit semen which induce antifertility antibodies. 7. Reprod. Fert. 13, 31.

Pernot, E. (1956) Recherches sur les constituants antigèniques des spermatozoïdes des cobayes. Bull. Soc. Chim. biol. 38, 1041.

RAO, S. S. \& SADRI, K. K. (1960) The antigenic composition of buffalo semen. J. comp. Path. Ther. 70, 1.

Stevens, K. M. \& Fost, C. A. (1964) Sperm and antibody production in rabbits following immunization with sperm and semen. Proc. Soc. exp. Biol. Med. 117, 125.

Tyler, A. (1961) Approaches to the control of fertility based on immunological phenomena. $\mathcal{J}$. Reprod. Fert. 2, 473.

WEIL, A. J. (1960) Immunological differentiation of epididymal and seminal spermatozoa of the rabbit. Science, N.Y. 131, 1040.

Weil, A. J. \& Finkler, A. E. (1958) Antigens of rabbit semen. Proc. Soc. exp. Biol. Med. 98, 794.

Weir, A. J., Kotsevalov, O. \& Wilson, L. (1956) Antigens of human seminal plasma. Proc. Soc. exp. Biol. Med. 92, 606.

WeIL, A. J. \& RoBerts, C. O. (1965) Fertility of female rabbits after iso-immunization with seminal plasma. Fert. Steril. 16, 356. 
Weil, A. J. \& Rodenburg, J. M. (1962) The seminal vesicle as the source of the spermatozoa-coating antigen of seminal plasma. Proc. Soc. exp. Biol. Med. 109, 567.

Williams, W. L., Weinman, D. E. \& Hamner, C. E. (1964) Effect of the female reproductive tract on spermatozoa. Proc. Vth int. Congr. Animal Reprod. 3, 367. 